\title{
PERFORMANCE ANALYSIS OF R22 AND ITS SUBSTITUTES IN AIR CONDITIONERS
}

\author{
S.K. Kalla ${ }^{1, *}$, B.B. Arora ${ }^{2}$, J.A.Usmani ${ }^{3}$
}

\begin{abstract}
The aim of this paper is to evaluate the performance of refrigerants R22, R407C, R432A, R438A and NM1 (R32/R125/R600a) in order to find a suitable alternative refrigerant for HCFC 22.

For this purpose energy as well as exergy analysis has been performed using NIST Cycle-D program for vapour compression refrigeration cycle design and TEWI (total equivalent warming impact) has also been computed for these refrigerants.

From the analysis it is found that the values of COP were nearer to those of R-22, e.g. at 25,45 and $55{ }^{\circ} \mathrm{C}$ condensing temperature, COP of R432a is lower than that of $\mathrm{R} 22$ by about $5.5 \%, 4 \%$ and $4.38 \%$ respectively. The results show that by considering the energetic efficiency, exergetic efficiency, TEWI and flammability simultaneously, R438A proves to be a better option to replace R22.
\end{abstract}

Keywords: Energy, Refrigerant, Energy, Cycle-D, Vapour Compression

\section{INTRODUCTION}

Across the globe research is going on to find a suitable substitute for R22. So far R22 has been the most versatile refrigerant for air conditioners. But R22 has an ODP of 0.055, and it is a controlled substance under the Montreal protocol. Developed countries have to eliminate R22 by 2030. Some countries have taken steps to eliminate hydro fluorocarbons earlier than the set deadline. From the year 2000, some countries including United States did not allow R22 to be used in new units. R22 has been predominantly used in air-conditioners. Since HCFC R22 is ozone depleting substance, decision was taken to gradually eliminate it [1]. For developed countries, the regulation for R22 production started from 1996. From 2010, USA has stopped manufacturing new equipment using R22.

R410A as well as R407C which are hydro fluorocarbon blends act as substitute for R22. However, they possess high global warming potential (1700-2000).

Thus to replace hydro fluorocarbons one can go for natural refrigerants which possess very low GWP. But due to their flammability issue hydrocarbon refrigerants have not been used in air conditioning applications $[2,3]$. But presently hydrocarbons are being explored to be used as refrigerants due to alarming degradation of environment. Some countries in Europe are utilizing hydrocarbons as refrigerants in heat pumps. It is well known that hydrocarbons offer low GWPs. Richardson and Butterworth used R-290 and R-600a refrigerants individually and their mixture [4].

ASHRAE specified R432A as a potential alternative to substitute R22 [5]. R432A is an azeotropic mixture. It is made up of $80 \%$ propylene and $20 \%$ dimethylether. R432A does not deplete ozone and possesses GWP of 5. It is having NBP of $-46.6^{\circ} \mathrm{c}$ with low temperature glide. R432A is one of the proposed alternative refrigerants for R22 which has been selected in this work to compare with other refrigerants by performing thermodynamic analysis.

Since India is a developing country, it comes under article -5 countries category. These countries eliminated the use of CFCs completely in 2010 [6]. In the past, refrigerants like methylene chloride have been used in air conditioning. But with the advent of CFCs and HCFCs in 1931, the above mentioned refrigerants became obsolete. Arrival of CFC and HCFC in air conditioning market was a big game changer. But it may also be mentioned that ammonia owing to its excellent thermodynamic properties continues to be used as a refrigerant e.g. in ice manufacturing factories. $\mathrm{CFC}$ and $\mathrm{HCFC}$ have been a success as a refrigerant because of their excellent

This paper was recommended for publication in revised form by Regional Editor Balaram Kundu

${ }^{1}$ Research Scholar, Department of Mechanical Engineering, Jamia Millia Islamia University, New Delhi, INDIA

${ }^{2}$ Department of Mechanical Engineering, Delhi Technological University, New Delhi, INDIA

${ }^{3}$ Department of Mechanical Engineering, Jamia Millia Islamia University, New Delhi, INDIA

${ }^{*} E$-mail address: skkalla@yahoo.com

Manuscript Received 20 July 2016, Accepted 22 April 2017 
properties. The halocarbons possess desirable properties like toxicity, non-flammable, non reactive with materials of construction and favorable thermo physical and thermodynamic characteristics. As a result, CFCs and HCFCs have found extensive use as a refrigerant in residential air conditioners and also in industrial refrigeration systems. Use of HCFCs as a refrigerant in air conditioning units have been controlled because they contribute to both ozone layer depletion a well as global warming which are disturbing issues. As a consequence, new substitutes are being explored to be used as a refrigerant in air conditioner. For retrofitting of existing R22 systems, refrigerant blends containing hydrofluorocarbons have been proposed as hydrofluorocarbons do not deplete ozone layer. Because hydrofluorocarbons possess high global warming impact, their use will not be continued long. Thus this motivation of searching a suitable alternative refrigerant is acting as a driving force in the field of research. Hydrocarbons foot this bill well.

Hydrocarbons (HCs) act as a substitute refrigerant in the field of air-conditioning. Hydrocarbons such as R290, R600A as well as their blends have been tried. These systems have to be manufactured for the requirement minimum quantity of HCs because HCs are flammable. To achieve this goal evaporators and condensers should be smaller. A refrigerant should possess certain thermo physical and chemical characteristics. While selecting a substitute refrigerant, these characteristics have to be considered. We select a particular refrigerant by considering the cooling capacity required as well as the required temperature. NBP of the refrigerant is most crucial in this selection. Most of the other thermodynamic characteristics very much depend on it.

Nowadays the twin issues of global warming and ozone depletion have to be considered side by side while searching for alternative refrigerants. Though HFCs possess high global warming potential their no ozone depletion property makes them attractive alternative to R22. Similarly, hydrocarbon refrigerants are resorted to in residential and industrial units. Kyoto protocol delineated six greenhouse gases and HFC was one of them. As per this protocol, which was accepted by India also, the emission of gases having high GWP which includes HFCs has to be reduced. HFC R134a is having high global warming impact and is instrumental in degradation of environment. That is why it cannot act as a long term substitute in refrigeration and air conditioning applications. It is well known that global warming impact of HFC is less than that of CFC but still it poses a great threat to environment.

Because of restrictions imposed by Montreal as well as Kyoto protocols, search is on for finding alternative refrigerants that are environmentally benign. For sustained development, we have to not only search for alternative refrigerants that are environmentally safe but we have to also take care of the energy efficiency of existing plants.

As far as air conditioning in residential, commercial and industrial segments is concerned, it is achieved at high cost. It is a difficult task to use less energy for air conditioning applications so that the associated power consumption is decreased and in turn to make them more efficient and environmental friendly. In order to find thermodynamic losses in different components of a unit, we need to perform quantitative analysis. By performing an in depth thermodynamic analysis of various processes of a system, we can optimize the given system to meet the set objectives. This results in proper design of the components of the system.

\section{LITERATURE SURVEY}

Lampugnani and Zgliczynski [7] studied R290 as a substitute of R502 and R22 in commercial refrigeration and air conditioning. They reported that the hermetic compressors, designed for use with R22, while operating with propane show a strong benefit in terms of general reliability, due to the lower bearing loads and the lower thermal level. It has a positive influence on the risk associated to the use of flammable refrigerants. Wang et al., [8] presented a rationally based model for evaluating the optimal refrigerant mass charge in refrigerating machines. They found that in the early stage of refrigerant charge process, a sharp rise of $\mathrm{COP}$ is observed. The COP reaches an optimal value for a specified refrigerant charge and shows a slight drop for a further increase of refrigerant charge.

Devotta et al. [9] carried out a performance assessment of HC-290 as a drop-in substitute to HCFC-22 in a window air conditioner. It was found that cooling capacity of HC-290 was lower in the range 6.6-9.7\%, energy consumption with HC-290 was lower in the range 12.4-13.5\% and discharge pressures of HC-290 were lower in the range $13.7-18.2 \%$. The same authors [10] also carried out performance assessment of HCFC-22 window air conditioner retrofitted with R-407C. They concluded that cooling capacity of R-407C was lower in the range 2.1- 
$7.9 \%$, power consumption with R-407C was higher in the range $6-7 \%$ and discharge pressures of R-407C were higher in the range $11-13 \%$.

Park et al. [11] analysed experimentally hydrocarbons and their mixtures with HFC R152a as a substitute to R22 air conditioners. It has been reported that COP of these mixtures is up to 5.7\% higher than that of R22. Mohanraj et. al. [12] reviewed environment friendly alternatives to halogenated refrigerants. He reported that the choice of alternative to R22 in air conditioning applications is R407C and R410 which are available in the Indian market. Wu et al. [13] performed a study of R161 Refrigerant for Residential Air conditioning applications. It was concluded that cooling capacity reduced $7.6 \%$, cooling EER increased $6.1 \%$, refrigerant optimized charge reduced $43 \%$ compared to R22 and R161 has lower discharge temperature.

Ramu et al. [14] carried out energy Performance Assessment of R32/R125/R600a mixtures as possible alternatives to R22 in compression refrigeration systems. They reported that VCC of new refrigerant mixture is closer to R22, COP of the mixture was found to be lower by about $16-20 \%$, compressor discharge temp of the new refrigerant mixture was observed to be $6-11^{\circ} \mathrm{C}$ lower, TEGWI of new refrigerant mixture was found to be higher than that of R22 by about $20 \%$. Kalla et al. [15] studied the comparative performance of R438A and R32/R125/R600A mixture for replacing HCFC22 used in residential air-conditioners and found R438A to be a better option. Kalla et al. [16] also performed a comparative energetic and exergetic analysis of R22, R438A and M1 and concluded that R438A was better than M1.

Taner [17] in his study presented the optimisation processes of energy efficiency for a drying plant and concluded that the optimisation of the mass and energy balance increased the current energy and exergy efficiencies. Taner and Sivrioglu [18] performed an energy-exergy analysis and optimisation of a model sugar factory in Turkey. They reported that the current turbine power process energy and exergy efficiencies were $46.4 \%$ and $27.7 \%$, respectively, and the optimized turbine power process energy and exergy efficiencies were $48.7 \%$ and $31.7 \%$, respectively.

Esen et al. [19] carried out the energy and exergy analysis of a ground-coupled heat pump system with two horizontal ground heat exchangers. Their results show that the energetic and exergetic efficiencies of the system increase when increasing the heat source (ground) temperature for heating season. Esen et al. [20] performed a techno economic appraisal of a ground source heat pump system for a heating season in eastern Turkey. It was shown that this system offers economic advantages over the mentioned five conventional heating methods. However, it is not an economic alternative system to natural gas.

Dixit et al. [21] performed energy and exergy analysis of absorption- compression cascade refrigeration system and reported that cascade condenser, compressor and refrigerant throttle valve are the major source of exergy destruction.

As the quest for finding a suitable alternative refrigerant for R22 in air conditioners goes on, this study carries out performance assessment of some chosen refrigerants. Refrigerants studied are not having any ozone depletion potential. NIST CYCLE_D [22] is the software that has been used for the simulation purpose. The refrigerants studied are R432a, R438a, R407C, and the blend of R32, R125 and R600a (referred to as NM1). NM1 was selected based on the reported work of Ramu et al. [14].

To the authors' knowledge, there is no specific work reported on the energy and exergy performance comparison of R407C, R432A, R438A and R32/R125/R600a mixture (referred to as NM1 in this paper) as an alternative to R22 in residential air conditioners. The main objective of this paper is to investigate which of these four refrigerant blends can be a potential alternative to R22.

\section{PHYSICAL AND MATHEMATICAL MODEL}

Figure 1 depicts the simplified diagram of the system and Figure 2 shows the pressure enthalpy diagram for a domestic air conditioning system. To perform thermodynamic analysis of the system, each component as a separate entity is considered [23].

\section{Energy Analysis}

Energy analysis deals with the first law of thermodynamics and provides us with an energy balance. To do this, as the present system is a flow process so steady state flow equation for a control volume based on conservation of energy can be expressed as under

$$
\dot{Q}-\dot{W}+\sum_{i}\left(h+\frac{v^{2}}{2}+g z\right) \dot{m}-\sum_{e}\left(h+\frac{v^{2}}{2}+g z\right) \dot{m}=\frac{d E_{c v}}{d t}
$$




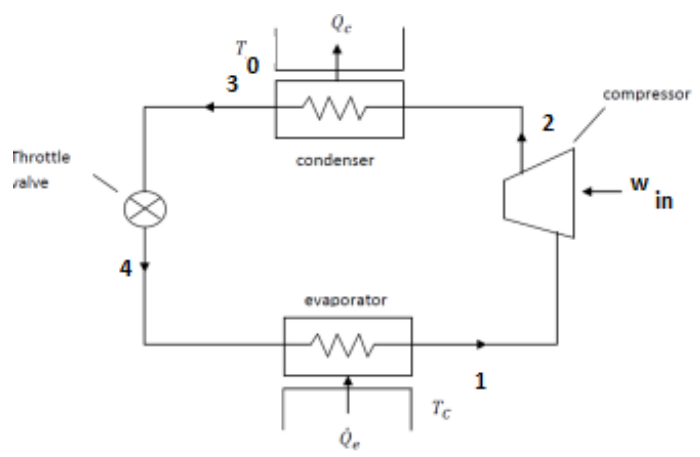

Figure 1. A schematic of the domestic air conditioning system

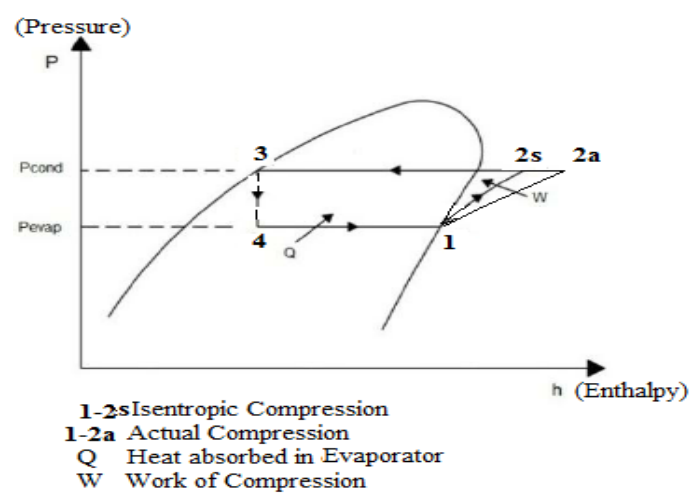

Figure 2. Schematic pressure versus enthalpy diagram for the air conditioning cycle

Rewriting the above equation for specific mass assuming one inlet (1) and one outlet (2) as under

$$
\mathrm{q}-\mathrm{w}=\left(\mathrm{h}_{2}-\mathrm{h}_{1}\right)+\left(\frac{\mathrm{v}_{2}^{2}}{2}-\frac{\mathrm{v}_{1}^{2}}{2}\right)+\mathrm{g}\left(\mathrm{z}_{2}-\mathrm{z}_{1}\right)
$$

where $\mathrm{w}$ is shaft work, $\mathrm{h}=\mathrm{u}+\mathrm{Pv}$ is the specific enthalpy, and the mass flow is $\dot{m}=\rho A v$. Being negligible the change in kinetic and potential energy is ignored. Compressor work is given by:

Actual work done

Adiabatic work

$$
\mathrm{w}_{\mathrm{act}}=\mathrm{h}_{2 \mathrm{a}}-\mathrm{h}_{1}
$$

$$
\mathrm{W}_{\text {is }}=\mathrm{h}_{2 \mathrm{~s}}-\mathrm{h}_{1}
$$

The isentropic efficiency is given by

$$
\eta_{i s}=\frac{w_{i s}}{w_{\text {act }}}
$$

Motor power which runs the compressor is given by

$$
w_{m}=\frac{w_{\text {act }}}{\eta_{\text {elec }}}
$$

where $\eta_{\text {elec }}$ is the electric motor efficiency.

Referring to Figures 1 and 2, energy balance equations in terms of components of the system are as under. 
Compressor

$$
\mathrm{q}_{\text {comp }}+\mathrm{W}_{\text {comp }}=\mathrm{h}_{2 \mathrm{a}}-\mathrm{h}_{1}
$$

Condenser

$$
\mathrm{q}_{\text {cond }}=\mathrm{h}_{2 \mathrm{a}}-\mathrm{h}_{3}
$$

Expansion_valve

$$
\mathrm{h}_{3}=\mathrm{h}_{4}
$$

Evaporator

$$
\mathrm{q}_{\mathrm{evap}}=\mathrm{h}_{1}-\mathrm{h}_{4}
$$

The COP of the system is given by

$$
\mathrm{COP}=\frac{\mathrm{q}_{\text {evap }}}{\mathrm{w}_{\mathrm{m}}}
$$

\section{Total Equivalent Warming Impact}

The method of calculating total equivalent warming impact (TEWI) is provided below [24]

TEWI = GWP (direct; refrigerant leaks incl. EOL) + GWP (indirect; operation)

$\left.=\left(\operatorname{GWP} \times m \times L_{\text {annual }} \times n\right)+\operatorname{GWP} \times m \times\left(1-\alpha_{\text {recovery }}\right)\right)+\left(\mathrm{E}_{\text {annual }} \times \beta \times n\right)$

Where:

$\mathrm{GWP}=$ Global Warming Potential of refrigerant, relative to $\mathrm{CO}_{2}\left(\mathrm{GWP} \mathrm{CO}_{2}=1\right)$

$L_{\text {annual }}=$ Leakage rate p.a. (Units: $\mathrm{kg}$ )

$N \quad=$ System operating life (Units: years)

$M \quad=$ Refrigerant charge (Units: $\mathrm{kg}$ )

$\alpha_{\text {recovery }}=$ Recovery/recycling factor from 0 to 1

$E_{\text {annual }} \quad=$ Energy consumption per year (Units: $\mathrm{kWh}$ p.a.)

$B \quad=$ Indirect emission factor (Units: $\mathrm{kg} \mathrm{CO}_{2}$ per $\mathrm{kWh}$ )

In this work, the $\mathrm{CO}_{2}$ emission factor is assumed to be $0.89 \mathrm{~kg}$ of CO $2 / \mathrm{kWh}$ (IEA, 2012).

\section{EXERGY ANALYSIS}

The same cycle as shown again in Figure 3, has been analyzed from exergy point of view. Energy analysis

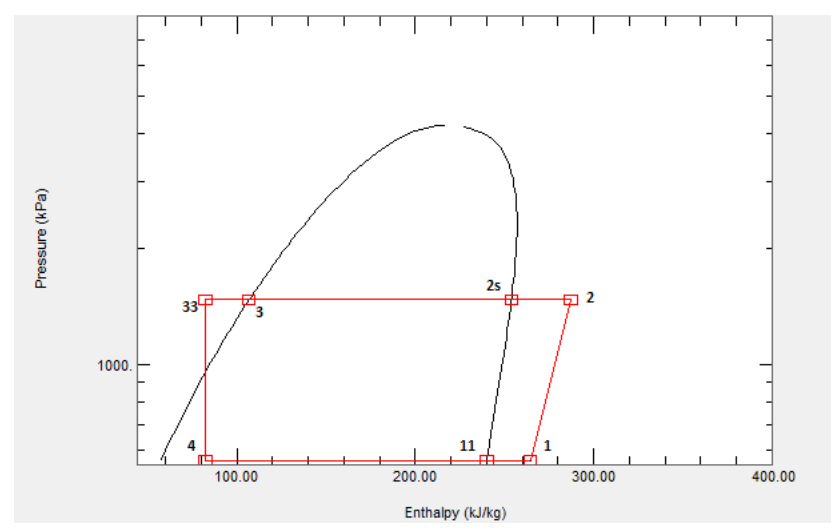

Figure 3. Pressure enthalpy diagram of vapour refrigeration system.

computes energy balance by taking into account quantities of energy. Whereas, exergy analysis which is based on the second law computes exergy balance by taking into account quality of energy and provides qualitative analysis. 
It identifies the component of the system which accounts for the highest exergy destruction. As a consequence we can bring in improvement in that component.

Using the control volume concept, exergy destroyed in a process undergoing steady state flow is given by $([25])$ :

$$
E \dot{D}_{\imath}=\Sigma\left(m \dot{e}_{x}\right)_{\text {in }}-\Sigma\left(m \dot{e}_{x}\right)_{\text {out }}+\left[\Sigma \left(\dot{Q}\left(1-\frac{T_{O}}{T}\right)_{\text {in }}-\Sigma\left(\dot{Q}\left(1-\frac{T_{O}}{T}\right)_{\text {out }}\right] \pm \Sigma \dot{W}\right.\right.
$$

where $\dot{E D_{\mathrm{i}}}$ is rate of exergy destruction.

Applying exergy destruction in evaporation process gives us:

$$
E \dot{D}_{e}=\dot{E}_{x_{4}}+\dot{Q}_{e}\left(1-\frac{T_{0}}{T_{r}}\right)-\dot{E}_{x_{11}}=\dot{m}_{r}\left(h_{4}-T_{0} s_{4}\right)+\dot{Q}_{e}\left(1-\frac{T_{0}}{T_{r}}\right)-\dot{m}_{r}\left(h_{11}-T_{0} s_{11}\right)
$$

Applying exergy destruction in compression process gives us:

$$
\dot{E} D_{c o m p}=\dot{E}_{x_{1}}+\dot{W}_{c o m p}-\dot{E}_{x_{2}}=\dot{m}_{r}\left(T_{0}\left(s_{2}-s_{1}\right)\right)
$$

Applying exergy destruction in condensation process gives us:

$$
\dot{E D_{c}}=\dot{E}_{x_{2}}-\dot{E}_{x_{3}}=\dot{m}_{r}\left(h_{2}-T_{0} s_{2}\right)-\dot{m}_{r}\left(h_{3}-T_{0} s_{3}\right)
$$

Applying exergy destruction in expansion process gives us:

$$
\dot{\mathrm{ED}} \dot{\mathrm{t}}_{\mathrm{x}}=\dot{\mathrm{E}}_{33}-\dot{\mathrm{E}}_{\mathrm{x}_{4}}=\dot{\mathrm{m}}_{\mathrm{r}}\left(\mathrm{h}_{33}-\mathrm{T}_{0} \mathrm{~s}_{3}\right)-\dot{\mathrm{m}}_{\mathrm{r}}\left(\mathrm{h}_{4}-\mathrm{T}_{0} \mathrm{~s}_{4}\right)=\dot{\mathrm{m}}_{\mathrm{r}}\left(\mathrm{T}_{0}\left(\mathrm{~s}_{4}-\mathrm{s}_{33}\right)\right)
$$

Applying exergy destruction in lvhe process gives us:

$$
\dot{E} D_{l v h e}=\dot{E}_{x_{3}}-\dot{E}_{x_{33}}+\dot{E}_{x_{11}}-\dot{E}_{x_{1}}=\dot{m}_{r}\left(\left(h_{3}-h_{33}+h_{11}-h_{1}\right)-T_{0}\left(\left(s_{3}-s_{33}+s_{1}-s_{11}\right)\right)\right.
$$

Combined exergy destruction is computed as:

$$
\Sigma \dot{E D_{i}}=\dot{E D_{e}}+\dot{E D_{c o m p}}+\dot{E D_{c}}+\dot{E D_{t}}+\dot{E} D_{l v h e}
$$

Exergetic efficiency is calculated as

$$
\eta_{e x}=\frac{\left|\dot{Q}_{e}\left(1-\frac{T_{0}}{T_{r}}\right)\right|}{\dot{W}_{c o m p}}
$$

\section{SIMULATION}

\section{Simulation by NIST Cycle_D Software (2004)}

Using this software, the various parameters for air conditioning system are compared using different alternative refrigerants for R22. The parametric investigations are made for single stage and double stage vapour compression cycle with heat exchanger.

\section{Simulation by NIST REFPROP Software (2007)}


By performing simulation with this software [26], comparison is done for the various thermal and physical properties of different refrigerants. The properties are compared with refrigerant $\mathrm{R} 22$. The variation of properties is studied for temperature range of $-20^{\circ} \mathrm{C}$ to $70^{\circ} \mathrm{C}$.

\section{Alternative refrigerants studied}

R432a

It is a blend of propylene (80\%) and dimethylether (20\%), a "drop-in” replacement refrigerant for R-22. It is a zeotropic mixture of hydrocarbons.

R438a

It is a blend of difluromethane (16\%), pentafluroethane (37\%), 1,1,1,2-tetrafluroethane (43\%), butane $(3.2 \%)$, isopentane $(0.8 \%)$ also an alternative of refrigerant for R22.

R407C

It is a mixture of difluromethane (23\%), pentafluoroethane $(25 \%)$, tetrafluroethane $(52 \%)$.

Blend of R32, R125 and R600a (referred to as NM1 in this study)

It is a blend of difluromethane (40\%), pentafluoroethane (40\%), isobutene $(20 \%)$.

\section{REFRIGERANT PROPERTIES}

\section{Variation of liquid density with temperature}

Variation of liquid density with temperature is shown in Figure 4. From this figure we observe that as the temperature is increased, the liquid density of all the refrigerants is decreased in same manner. Refrigerant NM1, which is having lower liquid density than R438A as well as R22, will have much lesser charge requirement.

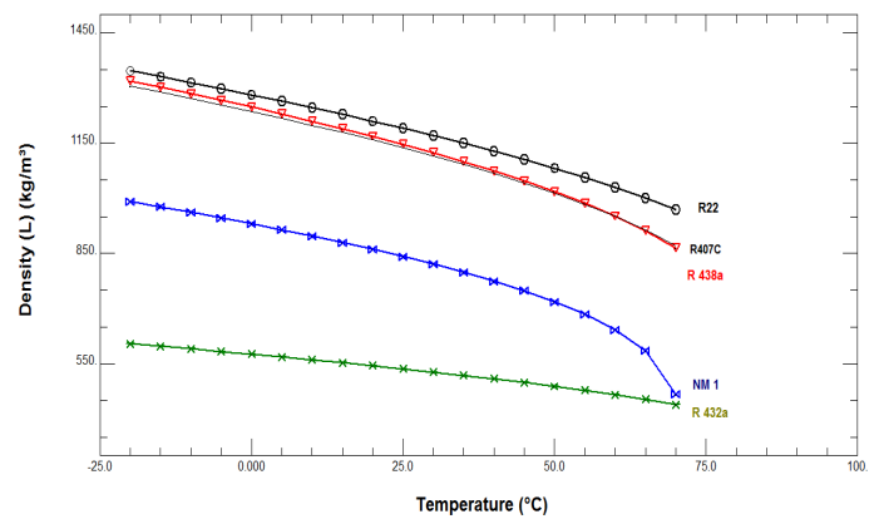

Figure 4. Variation of liquid density with temperature

\section{Variation of latent heat with temperature}

Change in latent heat with respect to temperature is shown in Figure 5. It is observed that as the temperature increases latent heat of all the refrigerants shows a downward trend. It is also found that R432A has a very high enthalpy which results in higher refrigeration capacity.

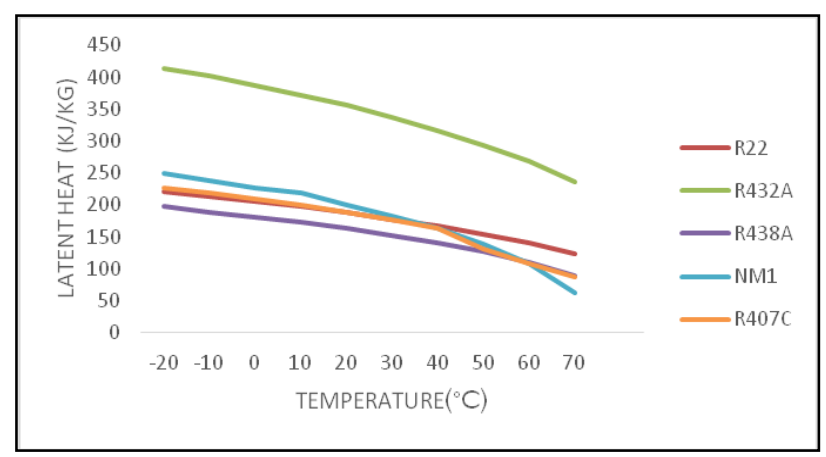

Figure 5. Variation of latent heat with temperature Variation of vapour pressure with temperature 
Variation of vapour pressure with temperature is shown in Figure 6. As the temperature is increased the vapour pressure of all the refrigerants is increased but for NM1 this effect is more pronounced than that of other refrigerants. Vapour pressure of all the refrigerants except that of NM1 is close to that of R22. For NM1 compressor will work at relatively higher pressure.

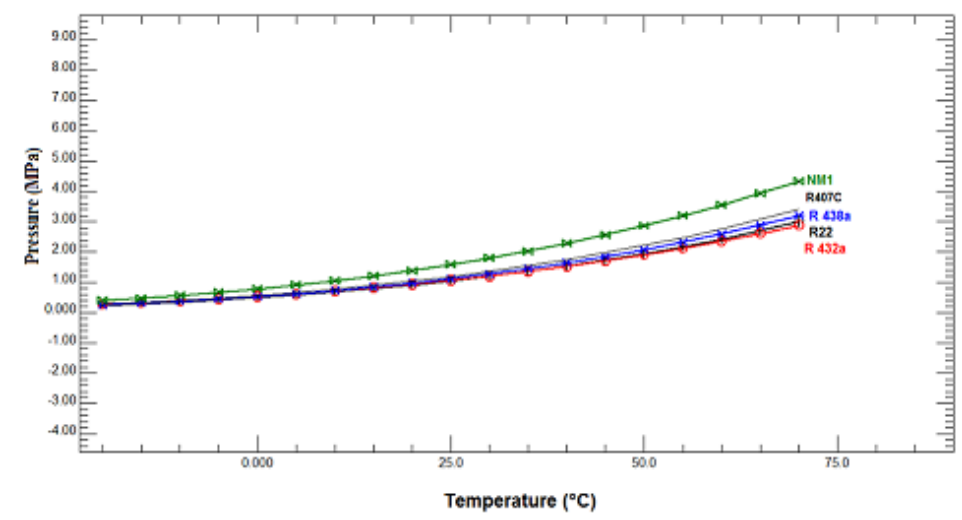

Figure 6. Variation of vapour pressure with temperature

\section{PERFORMANCE PARAMETERS}

Various performance parameters are analysed through simulation with the help of NIST CYCLE_D software (2007). Specifications of the refrigerating system are summarised in Table 1.

Table 1. Operating conditions of the refrigeration system

\begin{tabular}{|l|l|}
\hline Refrigeration capacity (Qev) & $7.03 \mathrm{KW}$ \\
\hline Evaporator temperature range (Tev) & $273-283 \mathrm{~K}$ \\
\hline Condenser temperature range (Tcond) & $298-328 \mathrm{~K}$ \\
\hline Compressor isentropic efficiency & $85 \%$ \\
\hline Compressor volumetric efficiency & $80 \%$ \\
\hline Electric motor efficiency & $70 \%$ \\
\hline
\end{tabular}

Refrigeration capacity of $7.03 \mathrm{~kW}$ is chosen for a window air conditioner of 2 tons. Evaporator temperature range of $0^{\circ}$ to $10^{\circ}$ is the range encountered in air conditioner. The average ambient temperature in summer is assumed to be $40^{\circ} \mathrm{C}$ and therefore the range for condenser temperature is taken from $25^{\circ}$ to $55^{\circ}$. Various efficiencies are taken as per ASHRAE, 1997.

\section{Variation of coefficient of performance with condensing temperature}

Figure 7 shows that COP of R432A is lower than that of R22 by about $5.02 \%, 2.96 \%$ and $2.54 \%$ at 25,45 and $55{ }^{\circ} \mathrm{C}$ respectively and it is quite closer to R22. The COP of NM1 and R438A is lower than that of R22 by about $22.64 \%, 20.95 \%, 24.58 \%$ and $14.45 \%, 12.37 \%, 14.60 \%$ at 25,45 and $55{ }^{\circ} \mathrm{C}$, respectively. The advantage of NM1 in terms of higher VCC is offset by its higher compressor work.

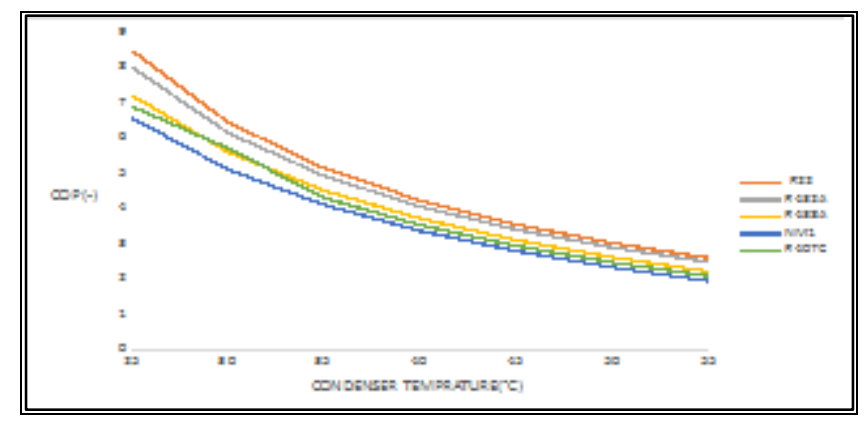

Figure 7. Variation of coefficient of performance with condensing temperature at evaporator temperature of $7.2^{\circ} \mathrm{C}$ 


\section{Variation of coefficient of performance with evaporator temperature}

Figure 8 shows that COP of R432A is lower than that of R22 by about $3.06 \%, 2.99 \%$ at 7.2 , and $8{ }^{\circ} \mathrm{C}$ respectively and it is quite closer to R22. The COP of NM1 and R438A is lower than that of R22 by about $26.11 \%$, $15.4 \%$ and $24.9 \%, 14.6 \%$ at $0^{\circ}$ and $7.2{ }^{\circ} \mathrm{C}$ respectively. $\mathrm{R} 438 \mathrm{~A}$ is having better COP due to its lower compressor work.

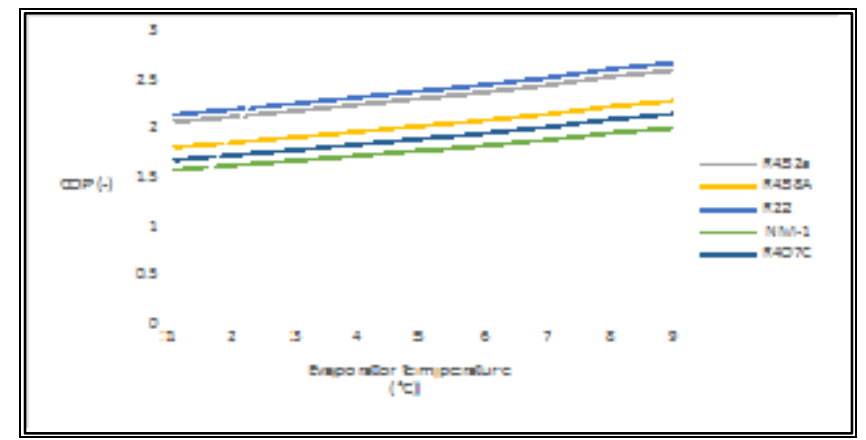

Figure 8. Variation of coefficient of performance with evaporator temperature at a condenser temperature of $55^{\circ} \mathrm{C}$

\section{Variation of volumetric cooling capacity with evaporator temperature}

Figure 9 shows that VCC of NM1 is higher than that of R22 by about $2.26 \%, 3.45 \%$ and $5.13 \%$ at 2,4 and $8{ }^{\circ} \mathrm{C}$ respectively and it is nearest to that of R22. Hence, NM1can be used as drop-in substitute without major modification in the existing R22 systems. As regards R438A, VCC is within $15 \%$ of R22 as the evaporating temperature varies from 2 to $10^{\circ} \mathrm{C}$.

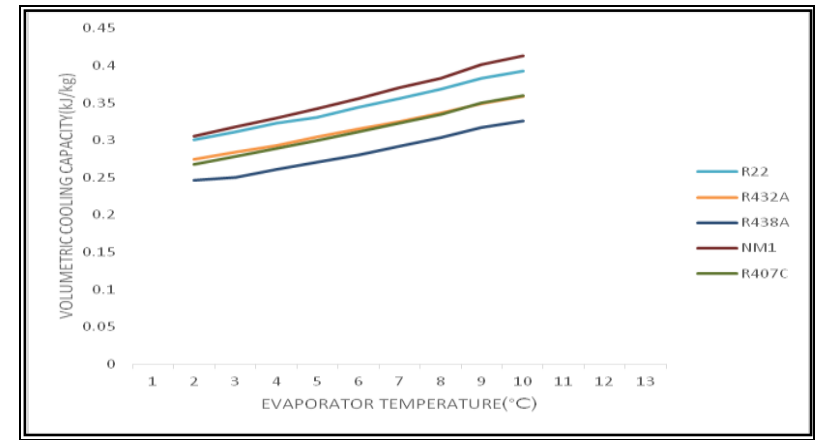

Figure 9. Variation of volumetric cooling capacity with evaporator temperature at condenser temperature of $40^{\circ} \mathrm{C}$

\section{Effect of isentropic efficiency on coefficient of performance}

Figure 10 indicates that COP increases as isentropic efficiency increases at almost the same rate for all the studied refrigerants. This is due to lesser irreversibility.

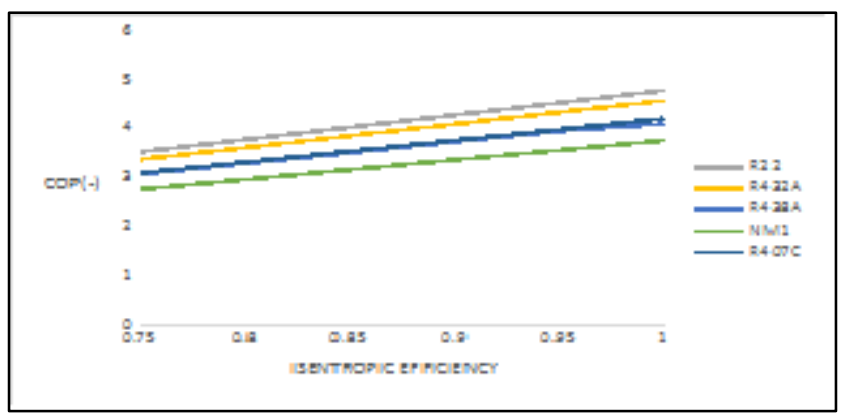

Figure 10. Effect of isentropic efficiency on coefficient of performance at evaporator temperature of $7.2^{\circ} \mathrm{C}$ and condenser temperature of $40^{\circ} \mathrm{C}$ 


\section{TOTAL EQUIVALENT WARMING IMPACT}

The TEWI of the five refrigerants is calculated for 15 year life time of the air conditioner at $50{ }^{\circ} \mathrm{C}$ and $-10^{\circ} \mathrm{C}$ condensing and evaporator temperatures, respectively. The TEWIs of the air conditioner working with R22, R432A, R438A, R407C and NM1 are shown in Figure 11. TEWI of R432A, R438A and NM1 was found to be higher than that of $\mathrm{R} 22$ by about $4.514 \%, 13.294 \%$ and $22.324 \%$ respectively.

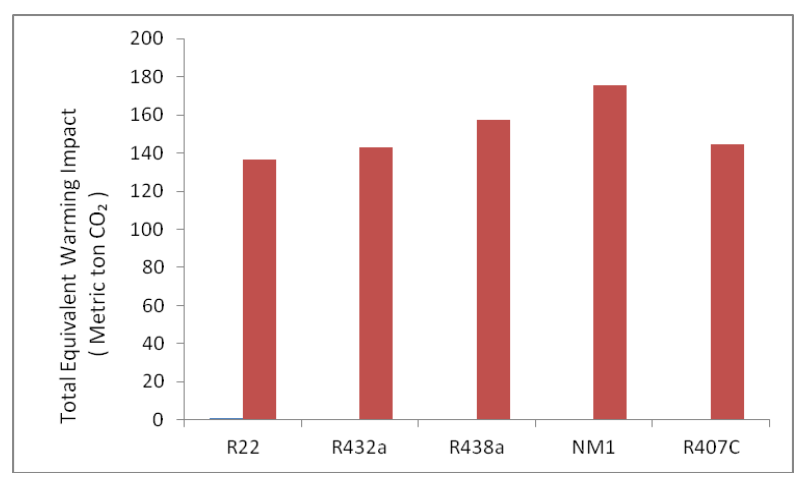

Figure 11. Total equivalent warming impact (TEWI) factor

\section{EXERGY ANALYSIS}

From energy analysis results refrigerants R438A and NM1 were found to be suitable candidates for R22 replacement. These two refrigerants were further investigated based on exergy analysis. Using the results of simulation, Figure 12 depicts the change of exergy efficiency of the three refrigerants with evaporator temperature at three different condensing temperatures i.e. $30^{\circ}, 40^{\circ}$ and $50^{\circ} \mathrm{C}$ at heat exchanger effectiveness of 0.5 . It is seen that exergy efficiency reduces as the evaporator temperature increases as well as with the increase in condensng temperature. The reduction in exergy efficiency is sharper at higher evaporating temperatures. Further, it is observed that exergy efficiency of R438A is nearer to R22 than NM1 at all evaporator as well as condenser temperatures. At $40^{\circ} \mathrm{C}$ condenser temperature and $-30^{\circ} \mathrm{C}$ evaporator temperature $\mathrm{R} 438 \mathrm{~A}$ is having $7.7 \%$ lower exergy efficiency than $\mathrm{R} 22$ whereas at $10^{\circ} \mathrm{C}$ it is $9.5 \%$ lower.

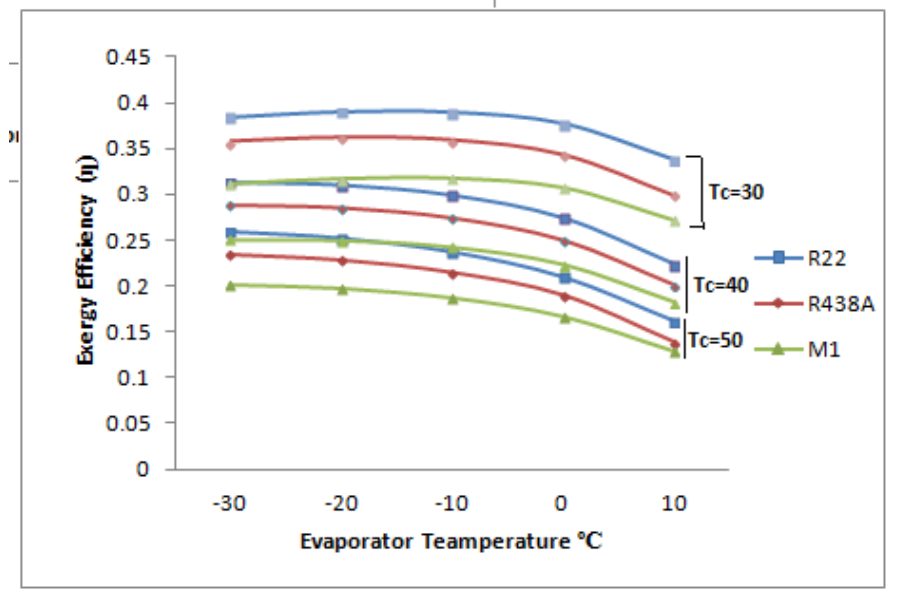

Figure 12. Variation of Exergy efficiency at heat exchanger effectiveness 0.5 and at various condenser temperature.

Using simulation results, Figure 13 depicts the change of total exergy destruction of the three refrigerants with evaporator temperature at three different condenser temperatures i.e. $30^{\circ}, 40^{\circ}$ and $50^{\circ} \mathrm{C}$ at heat exchanger effectiveness of 0.5 . It is seen that exergy destruction reduces as the evaporator temperature increases and it increases as the condenser temperature increases. The reduction in exergy destruction is steeper at lower evaporating temperatures and higher condenser temperatures. Also, it is seen that exergy destruction of R438A is nearer to R22 than NM1 at all evaporator as well as condenser temperatures. At $40^{\circ} \mathrm{C}$ condenser temperature and 
$-30^{\circ} \mathrm{C}$ evaporator temperature $\mathrm{R} 438 \mathrm{~A}$ is having $15.3 \%$ higher exergy destruction than $\mathrm{R} 22$ whereas at $10^{\circ} \mathrm{C}$ it is $15.5 \%$ higher.

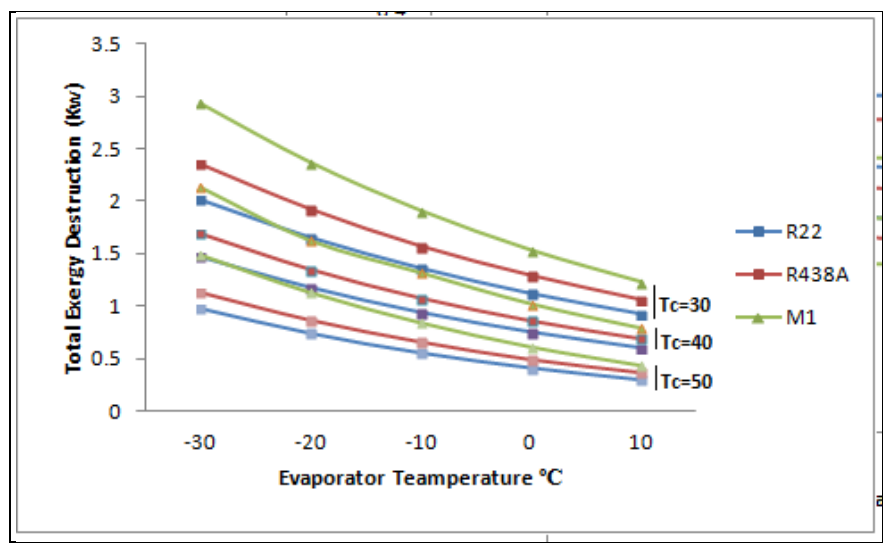

Figure 13. Total Exergy Destruction at heat exchanger effectiveness 0.5 at various condenser temperatures.

\section{DISCUSSION OF RESULTS}

After performing energy analysis of all the studied refrigerants, R438A and NM1 were found to be the promising alternatives to R22. Accordingly exergy performance of these two possible alternatives for R22 (R438A and a new refrigerant mixture NM1 (R32/R125/R600A)) have been compared in a theoretical study. The results point out that the energy as well as exergy efficiency of both the refrigerants are lesser than that of R22. However, $\mathrm{R} 438 \mathrm{~A}$ is a better option since its COP as well as exergy efficiency works out to be higher than that of NM1 throughout the evaporator and condenser temperature range. At $40^{\circ} \mathrm{C}$ condenser temperature and $10^{\circ} \mathrm{C}$ evaporator temperature, $\mathrm{COP}$ of R438A is higher by $10.8 \%$ as compared to $\mathrm{M} 1$ whereas the corresponding exergy efficiency is higher by $9.8 \%$

\section{CONCLUSION}

- The performance of four refrigerants as possible alternatives to R-22 was studied with the help of CYCLE_D software. The values of COP were nearer to those of R-22, e.g. at 25,45 and $55^{\circ} \mathrm{C}$ condensing temperature, COP of R432a is lower than that of $\mathrm{R} 22$ by about $5.5 \%, 4 \%$ and $4.38 \%$ respectively.

- By resorting to hydrocarbon refrigerant as a substitute to R-22 we can reduce global warming and avoid ozone layer damage due to use of other refrigerants. However, the drawback of hydrocarbon refrigerants is their flammability due to which safety measures during their use is essential.

- $\quad$ R407C needs synthetic lubricant.

- The TEWI of the four refrigerants is calculated for 15 year life time of the air conditioner at $50{ }^{\circ} \mathrm{C}$ and $-10^{\circ} \mathrm{C}$ condensing and evaporator temperatures, respectively. The TEWIs of the air conditioner working with R22, R432A, R438A and NM1 are compared.

- $\quad$ R438A is a better option since its COP as well as exergy efficiency works out to be higher than that of NM1 throughout the evaporator and condenser temperature range.

Till the safety concerns for use of hydrocarbons like R432A in air conditioners are addressed to, R438A seems to be an appropriate alternative to $\mathrm{R} 22$.

\section{NOMENCLATURE}

Act

ASHRAE

CFC

COP

Comp
Actual

American Society of Heating,

Refrigerating, and Air-Conditioning

Engineers

Chlorofluorocarbon

Coefficient of Performance

Compressor 


$\begin{array}{ll}\text { Cond, c } & \text { Condenser } \\ \mathrm{Cv} & \text { Control volume } \\ \mathrm{E}_{\mathrm{d}} & \text { Exergy destruction } \\ \mathrm{E} & \text { Energy, Exit }(\mathrm{kJ},-) \\ \text { Evap } & \text { Evaporator } \\ \mathrm{Exp} & \text { Expansion device } \\ \mathrm{GWP} & \text { Global Warming Potential } \\ \mathrm{G} & \text { Acceleration due to gravity }\left(\mathrm{m} / \mathrm{s}^{2}\right) \\ \mathrm{HC} & \text { Hydrocarbon } \\ \mathrm{HCFC} & \text { Hydrochlorofluorocarbon } \\ \mathrm{HFC} & \text { Hydrofluorocarbon } \\ \mathrm{H} & \text { Specific enthalpy }(\mathrm{kJ} / \mathrm{kg}) \\ \dot{m} & \text { Mass flow rate }(\mathrm{kg} / \mathrm{s}) \\ \mathrm{NBP} & \text { Normal Boiling Point }\left({ }^{\circ} \mathrm{C}\right) \\ \mathrm{ODP} & \text { Ozone Depleting Potential } \\ \mathrm{P} & \text { Pressure }(\text { MPa }) \\ \mathrm{POE} & \text { Polyol Ester } \\ \mathrm{Q} & \text { Heat Transfer }(\mathrm{kJ}) \\ \dot{Q} & \text { Heat transfer per unit mass }(\mathrm{kJ} / \mathrm{kg}) \\ \mathrm{T} & \text { Temperature }(\mathrm{K}) \\ \mathrm{TEWI} & \text { Total Equivalent Warming Impact } \\ \mathrm{U} & \text { Internal energy per unit mass }(\mathrm{kJ} / \mathrm{kg}) \\ \mathrm{VCRS} & \text { Vapour Compression Refrigeration Cycle } \\ \mathrm{V} & \text { Velocity, volume }\left(\mathrm{m} / \mathrm{s}, \mathrm{m}^{3}\right) \\ \mathrm{W} & \text { Work interaction }(\mathrm{kJ}) \\ \dot{W} & \text { Work interaction per unit mass }(\mathrm{kJ} / \mathrm{kg}) \\ \mathrm{Z} & \text { Height from datum }(\mathrm{m}) \\ & \end{array}$

\section{REFERENCES}

[1]Protocol, M. (1987). Montreal protocol on substances that deplete the ozone layer. Washington, DC: US Government Printing Office, $26 . \quad 128-136$. [2]Richards, R.-G.; Shankland, I.-R. (1992) Flammability of alternative refrigerants. ASHRE J., 34, 4. [3]Ritter, T.-J. (1996) In: Flammability-hydrocarbon refrigerants, Proceedings of the Institute of Refrigeration Conference, Safe and Reliable Refrigeration, London, [4]Richardson, R. N., \& Butterworth, J. S. (1995). The performance of propane/isobutane mixtures in a vapourcompression refrigeration system. International Journal of Refrigeration, 18(1), 58-62. [5]ANSI/ASHRAE Addenda a, b, c, d, e, f, g, and h to ANSI/ASHRAE Standard 34 (2007), Designation and safety classification of refrigerants. [6] Powell, R. L. (2002). CFC phase-out: Have we met the challenge? Journal of Fluorine Chemistry, 114(2), 237250.

[7]Lampugnani, G., \& Zgliczynski, M. (1996). R290 as a Substitute of R502 and R22 in Commercial Refrigeration and Air Conditioning. International Compressor Engineering Conference. [8]Vjacheslav, N., Rozhentsev, A., \& Wang, C. C. (2001). Rationally based model for evaluating the optimal refrigerant mass charge in refrigerating machines. Energy Conversion and Management, 42(18), 2083-2095. [9]Devotta, S., Padalkar, A. S., \& Sane, N. K. (2005). Performance assessment of HC-290 as a drop-in substitute to HCFC-22 in a window air conditioner. International Journal of Refrigeration, 28(4), 594-604. [10]Devotta, S., Padalkar, A. S., \& Sane, N. K. (2005). Performance assessment of HCFC-22 window air conditioner retrofitted with R-407C. Applied Thermal Engineering, 25(17-18), 2937-2949. [11]Park, K. J., Seo, T., \& Jung, D. (2007). Performance of alternative refrigerants for residential air-conditioning $\begin{array}{llll}\text { applications. } & \text { Applied } & \text { Energy, } & \text { 84(10), }\end{array}$ [12]Mohanraj, M., Jayaraj, S., \& Muraleedharan, C. (2009). Environment friendly alternatives to halogenated refrigerants-A review. International Journal of Greenhouse Gas Control. 
[13]Wu, Y., Liang, X., Tu, X., \& Zhuang, R. (2012). Study of R161 refrigerant for residential air-conditioning applications.

[14]Ramu, N. S., \& Kumar, P. S. (2014). Energy performance assessment of R32/R125/R600a mixtures as possible alternatives to R22 in compression refrigeration systems. [15]Kalla, S. K., Arora, B. B., \& Usmani, J. A. Comparative Performance of R438A and R32/R125/R600A Mixture for Replacing HCFC22 used in Air-Conditioners. [16]Kalla, S.K.; Arora, B.B.; Usmani, J.A. (2015) In: Comparative Energetic and Exergetic Analysis of R22, R438A and M1, The 2nd International Conference on The Recent developments in Science, Engineering and Technology (REDSET 2015), 30-31 October 2015, GD Goenka University Gurgaon, India. [17]Taner, T. (2015). Optimisation processes of energy efficiency for a drying plant: A case of study for Turkey. Applied Thermal Engineering, $\quad 80, \quad 247-260$. [18]Taner, T., \& Sivrioglu, M. (2015). Energy-exergy analysis and optimisation of a model sugar factory in Turkey. $\begin{array}{lll}\text { Energy, } & 641-654 .\end{array}$ [19]Esen, H., Inalli, M., Esen, M., \& Pihtili, K. (2007). Energy and exergy analysis of a ground-coupled heat pump system with two horizontal ground heat exchangers. Building and Environment, 42(10), 3606-3615. [20]Esen, H., Inalli, M., \& Esen, M. (2006). Technoeconomic appraisal of a ground source heat pump system for a heating season in eastern Turkey. Energy Conversion and Management, 47(9-10), 1281-1297. [21]Dixit, M., Arora, A., \& Kaushik, S. C. (2016). Energy and exergy analysis of a waste heat driven cycle for triple effect refrigeration. Journal of Thermal Engineering, 2(5), 954-961. [22]CYCLE _D vapour compression cycle design (2004), NIST Standard reference database 49-version 4.0.Gaithersberg, MD:National institute of standards and technology. [23]Wark, K. Jr., (1995) Advanced Thermodynamics for Engineers; McGraw-Hill: Singapore. [24]AIRAH. Methods of calculating Total Equivalent Warming Impact (TEWI) (2012) Best practice guidelines available from http:/www.iea.org/publications/freepublications/publication/name,32870, en.html. [25]Arora, A., Arora, B. B., Pathak, B. D., \& Sachdev, H. L. (2007). Exergy analysis of a vapour compression refrigeration system with R-22, R-407C and R-410A. International journal of Exergy, 4(4), 441-454. [26]NIST Standard Reference Database 23 (2007). NIST Thermodynamic and Transport Properties of Refrigerants and Refrigerant Mixtures. National Institute of Standards and Technology, REFPROP Version 8.0. 